\title{
An Intelligent Managing System of Electric Energy Based on ST7538
}

\author{
Qiu-xia Liu \\ Department of Physics and Electronic Engineering, Heze University, Heze \\ Shandong 274015, China \\ liuqiuxia66@163.com
}

\begin{abstract}
To improve the scientific and automatic management of power consumption and meet with the intelligentized management of using and providing power, on the basis of modifying inductive watt-hour meter, an intelligent managing system of electric energy based on ST7538 has been developed. The scheme of the intelligent system is put forward, diagram of hardware of the system is provided, we choose Visual Basic to develop software control and SQL Server2012 for its DBMS. The intelligent system integrates with information collection, information transition, information procession and some other technology, it overcomes the abuse of meter-reading manually. The intelligent system realizes many functions such as automatic meter-reading, real time query and so on. It has a variety of advantages such as high economical efficiency, good expansibility and so on. If the system is applied into the power system, it can bring large economic profit and social efficiency.
\end{abstract}

Keywords: Power Line Carrier, ST7538, Intelligent Management, Watt-hour meter, VB

\section{Introduction}

With the development of micro-electric technology, computer technology and corresponding technology, intelligent levels of offices, industries and homes have been improved greatly. To meet with the social requirements and adapt the needs for the intelligent management of electric energy, the intelligent managing system of electric energy has been developed. The system solves the problems of collecting electric energy, it realizes the intelligent management of electric energy, in this way, and it saves manpower and resources. The intelligent system can also analyze collected data intelligently, so it is able to provide all kinds of data and scientific basis for administers, at the same time, it can offer important and instructional information to decision-makers [1]. Therefore, the development of intelligent managing system for electric energy based on ST7538 has practical and applied values for managing electric energy.

\section{Hardware Design of the System}

\subsection{Structure Diagram of the System}

The intelligent managing system integrates with micro-electronic technology, automatic control technology, communication technology and computer technology, using distributed structure and modular design, all equipment has microprocessors, they can operate independently. The intelligent managing system can achieve the intelligent management of watt-hour meters in a city, a region, or factories [2]. The intelligent managing system remoulds the machinery Watt-hour meter, it gets information of Watt-hour meters and sends instructions by power line 
communication, power consumptions are counted by single- chip microcomputer AT89C51, using the microcomputer to manipulate the database files, it can achieve for each watt-hour meter reading, statistics, analysis, accounting, query and print functions. The intelligent managing system is mainly made of the central station, acquisition station, terminal station and watt-hour meter, the structure diagram of the system is shown in Figure 1.

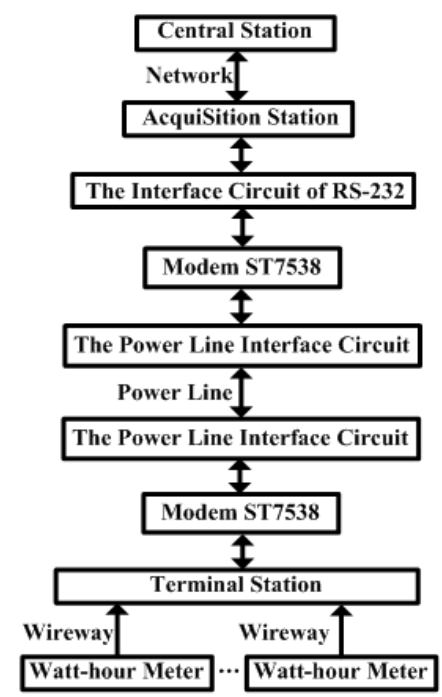

Figure 1. Structure Diagram of the System

\subsection{Power Circuit}

Power circuit is shown in Figure 2, they are mainly composed of a power transformer, rectifier circuit, filter circuit and a voltage stabilizing circuit. 220V AC voltage is changed into the needed voltage by the $9 \mathrm{~V}$ power transformer, the needed voltage is changed into DC voltage of $+12 \mathrm{~V}$ through the rectification circuit, and then it provides power to the modem ST7538, finally, the DC voltage of $+5 \mathrm{~V}$ is output by the filter circuit and the regulator circuit [3]. The DC voltage of $+5 \mathrm{~V}$ provides power to microprocessor AT89C51, the control circuit, the clock circuit, storage circuits and other circuits.

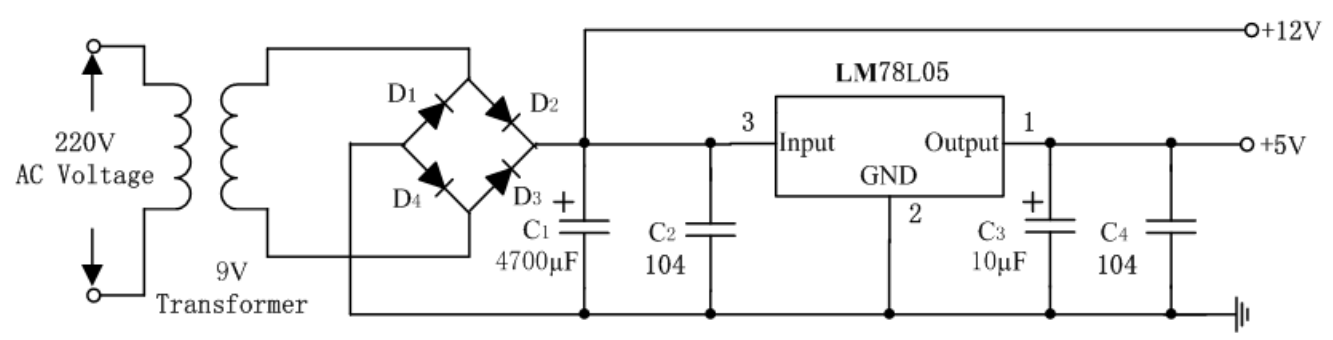

Figure 2. Power Circuit

\subsection{Central Station}

The central station is actually a software management system established on the basis of database. It is responsible for collecting and dealing with the data of acquisition stations in a larger region, and then automatically in a proper way to collect the charges for electricity from users. According to different needs, the central station can also do different setup and maintenance for acquisition stations, terminal stations and watt-hour meter. For example, it can set up network addresses of 
acquisition stations and increase parameters of users [4]. The central station and the acquisition station is a one-to-many relationship, a central station can manage 256 acquisition stations, and the central station can be installed in the power supply or tariff collection department.

\subsection{Acquisition Station}

The acquisition station is the face of an area, such as a cell or more buildings; it can be widely used for urban and rural residents and enterprises with the power management. The acquisition station is the link between the central station and terminal station, it is the core part of the whole system, it can be directly installed in the transformer room, the acquisition station can realize automatic two-way data communications with terminal stations on the same transformer, the means of communication between acquisition stations and terminal stations is power line carrier [5]. System software is designed by Visual Basic, SQL Server2012 is used for its DBMS, acquisition stations are designed by the modular programming, it is convenient to extend the system, the system has friendly interface and it is conveniently to operate.

\subsection{The Power Line Interface Circuit}

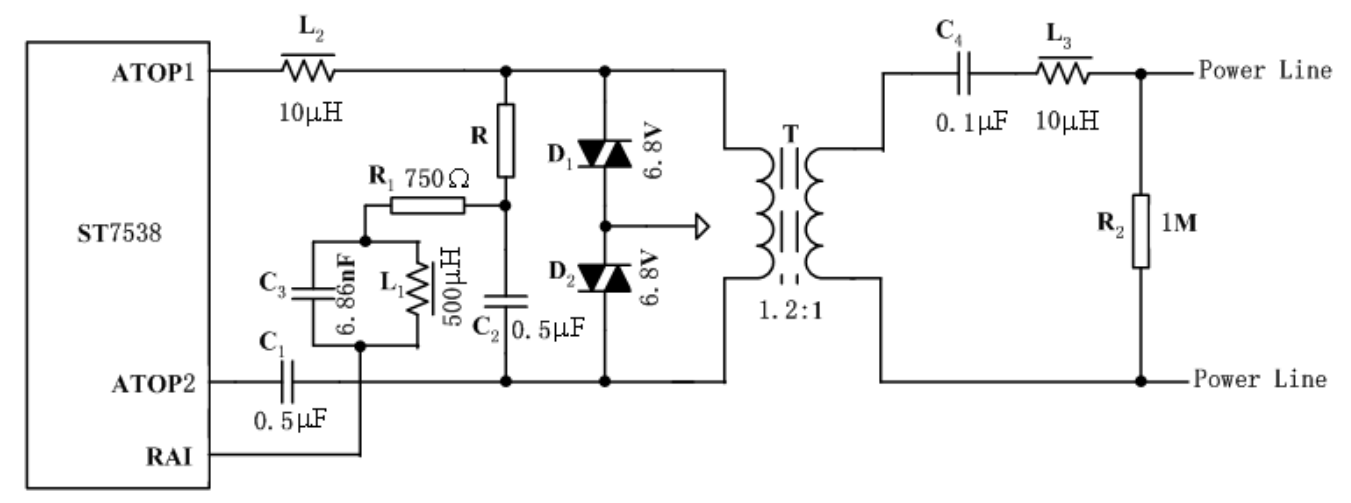

Figure 3. The Power Line Interface Circuit

In the past ten years, the power line modem has a great breakthrough in many aspects, such as modulation and demodulation technology, energy-saving technology, network technology and so on. In the intelligent managing system of electric energy, we select the chip ST7538 as the power line modem. ST7538 is a new type of power line modems developed by the SGSTHOMSON Company on the base of ST7536, ST7537, it is the upgrade products. ST7538 is a Half Duplex synchronous/asynchronous FSK Modem designed for power line communication network application. It operates from a single supply voltage and integrates a line drive and a $5 \mathrm{~V}$ linear regulator. The device operation is controlled be means of an internal register, programmable through the synchronous serial interface. Additional functions as watchdog, clock output, output voltage and current control, preamble detection, time-out, band in use are included. ST7538 is a low voltage power line modem according to the bad channel environment in power network, its signal-to-noise ration, performances of the data transmission and transmission rate of data have been greatly improved. The fifth generation technology, digital signal processing and other advanced technology make ST7538 in anti-jamming, anti-fading performance, performance and price of similar products at home and abroad have a more outstanding performance. According to the characteristic of ST7538, from China's actual conditions, using the method of combination of theory and experiment, we have designed a power line interface circuit [6], the interface circuit has high efficiency and good performance, its circuit is shown in Figure 3. 


\subsection{The Terminal Station}

The terminal station is based on AT89C51, it can collect, store and transmit information of watt-hour meters, it can also display the working state [7]. The terminal station is mainly made of pulse counting module, communication module, clock circuit, working state display module, power control circuit and keyboard module, its basic components is shown in Figure 4.

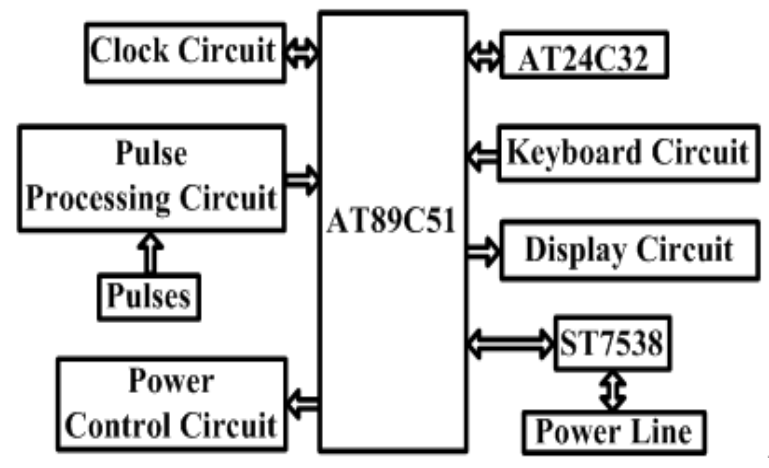

Figure 4. The Basic Components of Terminal Station

\subsection{Watt-hour Meter}

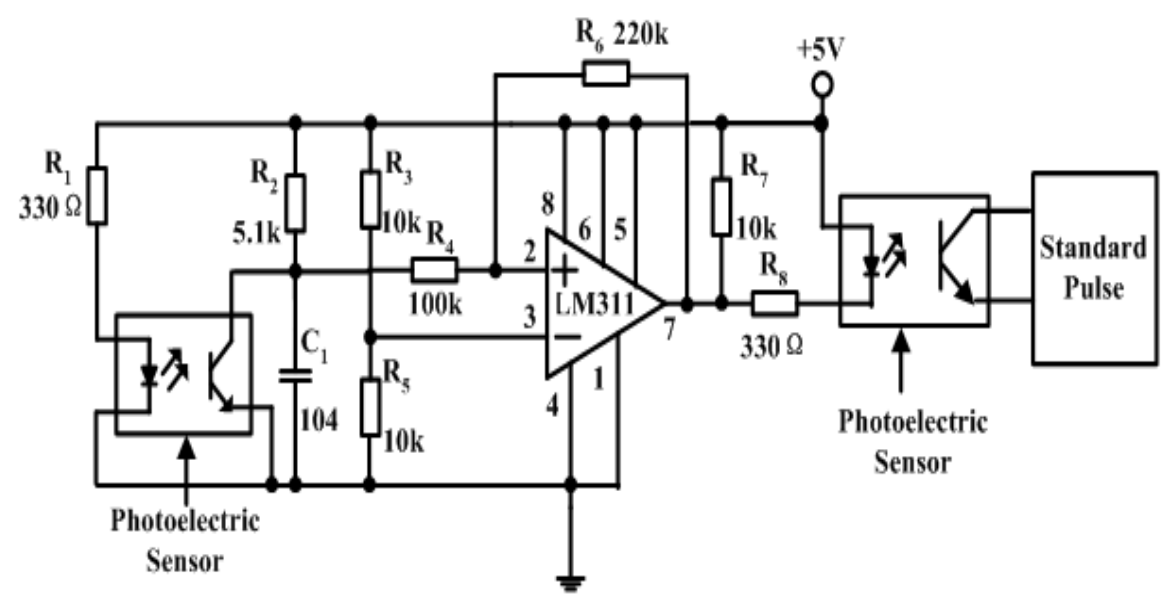

Figure 5. The Transformation Circuit of Mechanical Watt-Hour Meter

Watt-hour meter is the basic part of the whole system, its selection has crucial effect on the intelligent managing system of electric energy, and therefore, in consideration of the advanced type and economy, its reliability and accuracy of the measurement should be considered. The automatic management of power system needs to collect pulses, because original mechanical watt-hour meters has single function, they are not adapt to the demands of the automatic management of power system. Methods of converting the electric energy of consumption into pulses are using pulse meters and adding pulse converting module to mechanical watt-hour meters. Due to lightning resistance, life, reliability and performance of meters should be further tested, the maximum amount of mechanical watt-hour meters, their reliabilities have been proved in practice, considering mechanical watt-hour meters are mostly used at present, so they will not been abandoned [8]. In the intelligent managing system of electric energy, the pulse meter we used is the transformation on the base of the mechanical watt-hour meter; its transformation circuit is shown in Figure 5. 


\section{Software Design of the System}

\subsection{Software Design of the Terminal Station}

The software control between the terminal station and the acquisition station is realized by $\mathrm{C}$ programming language, the control function of the single chip AT89C51 is achieved with the help of the powerful $\mathrm{C}$ language $[7,9,10]$. When the terminal station completes collecting, storing and proceeding pulses, it waits for receiving commands sent from the acquisition station, if the command is received; the terminal station makes corresponding treatment according to the command. The flow chart of the main program, the flow chart of collecting pulses and the flow chart of sending data are respectively shown in Figure 6, Figure 7 and Figure 8.

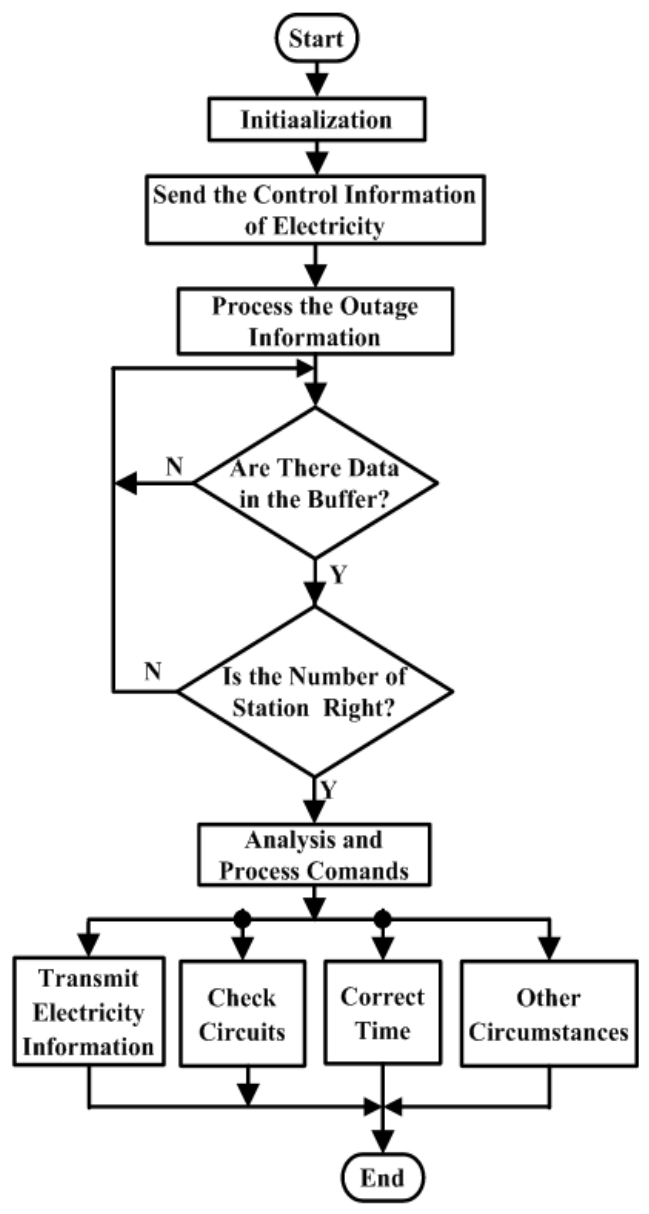

Figure 6. The Flow Chart of the Main Program 


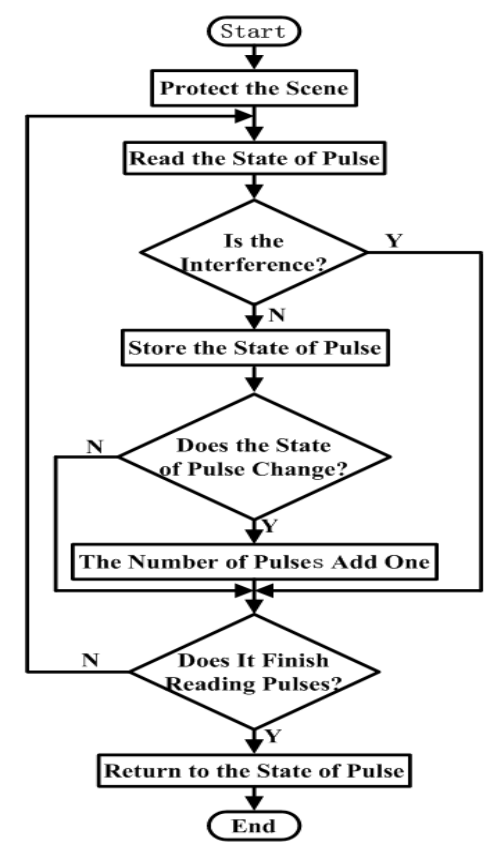

Figure 7. The Flow Chart of Collecting Pulses

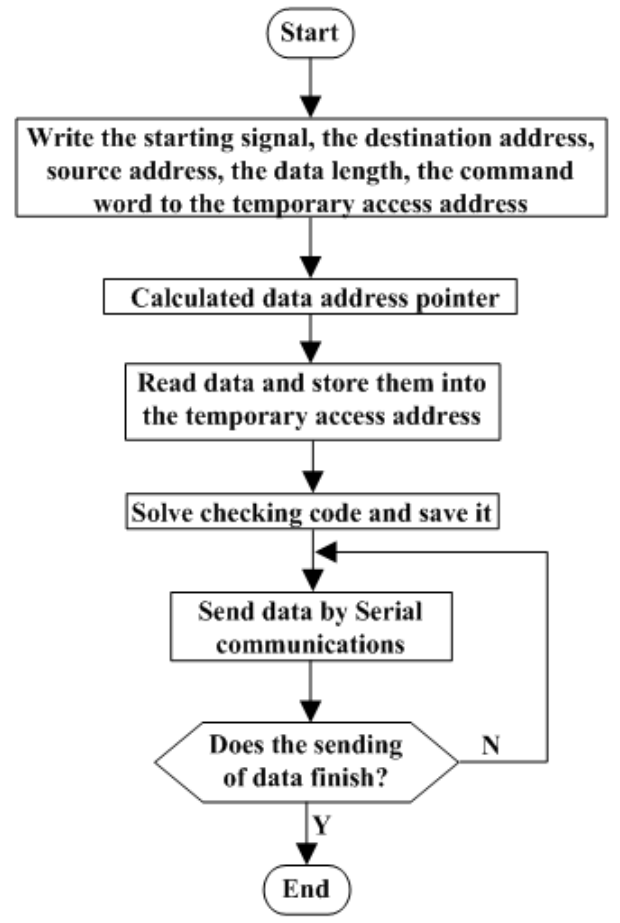

Figure 8. The Flow Chart of Sending Data

\subsection{Software Design of the Acquisition Station}

The acquisition station of the intelligent managing system uses the client/server system structure. The server uses SQL server as its database, the main function of the acquisition station is completed by the software VB [11, 12]. Using VB to develop Client/Server application has the following advantages.

(1) Reusability: Functions packaged to each component can be shared and reused by many applications. 
(2) Work can be distributed from the desktop to the more powerful network server, it can help to solve the requirements of performance and bandwidth.

(3) Large complex projects can be divided into simple, easier assembly project.

(4) The modification of business processing logic on the server in centralized deployment becomes easier.

Main functional block diagram of the acquisition station is shown in Figure 9.

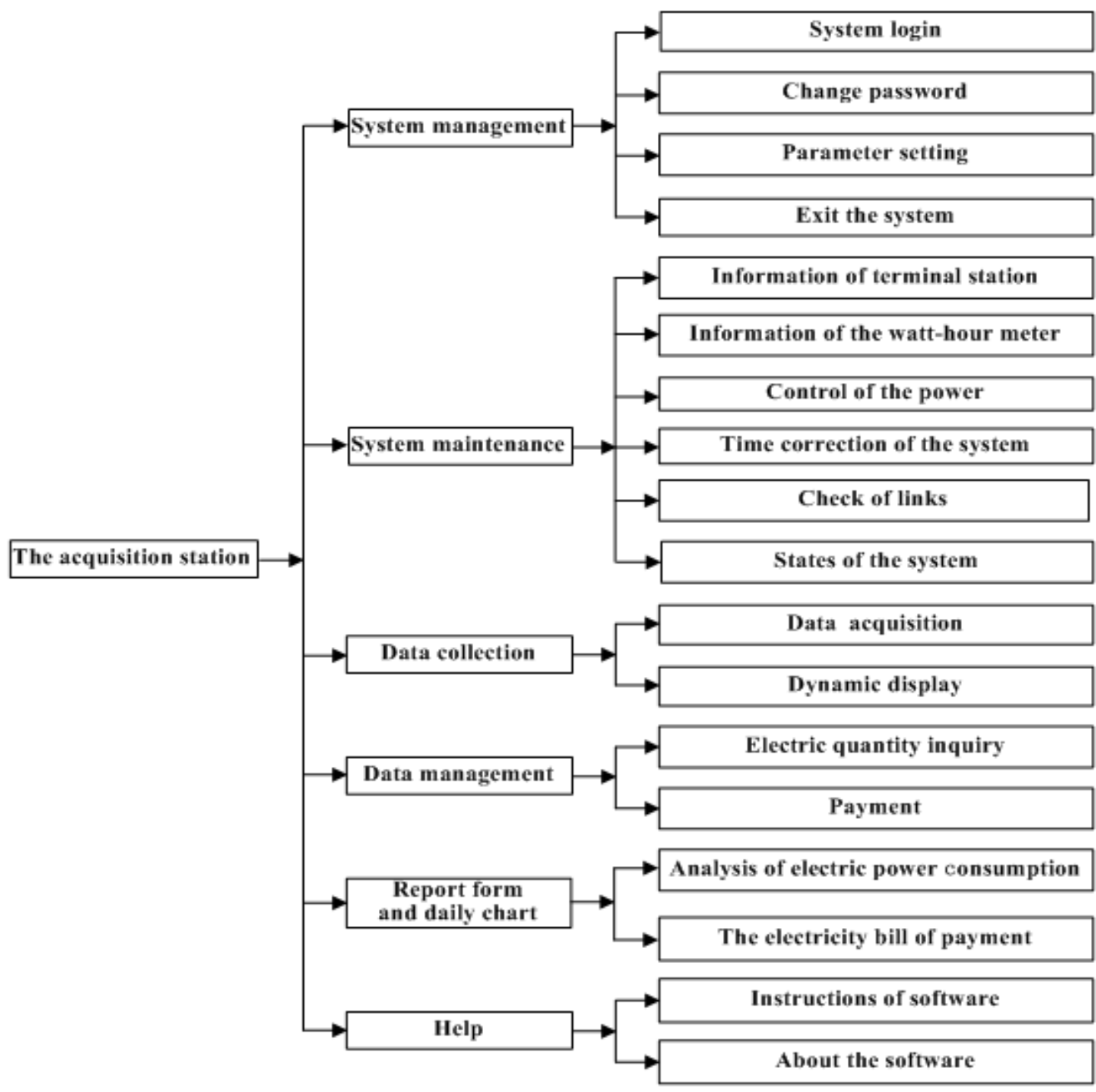

Figure 9. Main Functional Block Diagram of the Acquisition Station

\section{Test of the System}

The intelligent managing system has been developed and tested, and it has been on trial in the Heze University north building 7 and building 8, transmitted data are accurate, its running is in good condition. According to the feedback information, the system achieves the requirement basically. The function, reliability and other indexes of hardware and software are in line with China's power sector requirements. The operation interface of managing subsystem, the operation interface of collecting data automatically, the interface of checking links, the interface of control of the power, the interface of electric quantity inquiry and the interface of the electricity bill of payment are respectively shown in Figure 10, Figure 11, Figure 12, Figure 13, Figure 14, Figure 15. The partial information related to watt-hour meters of the No. 3 terminal station in March 17, 2013 is shown in Table 1. 


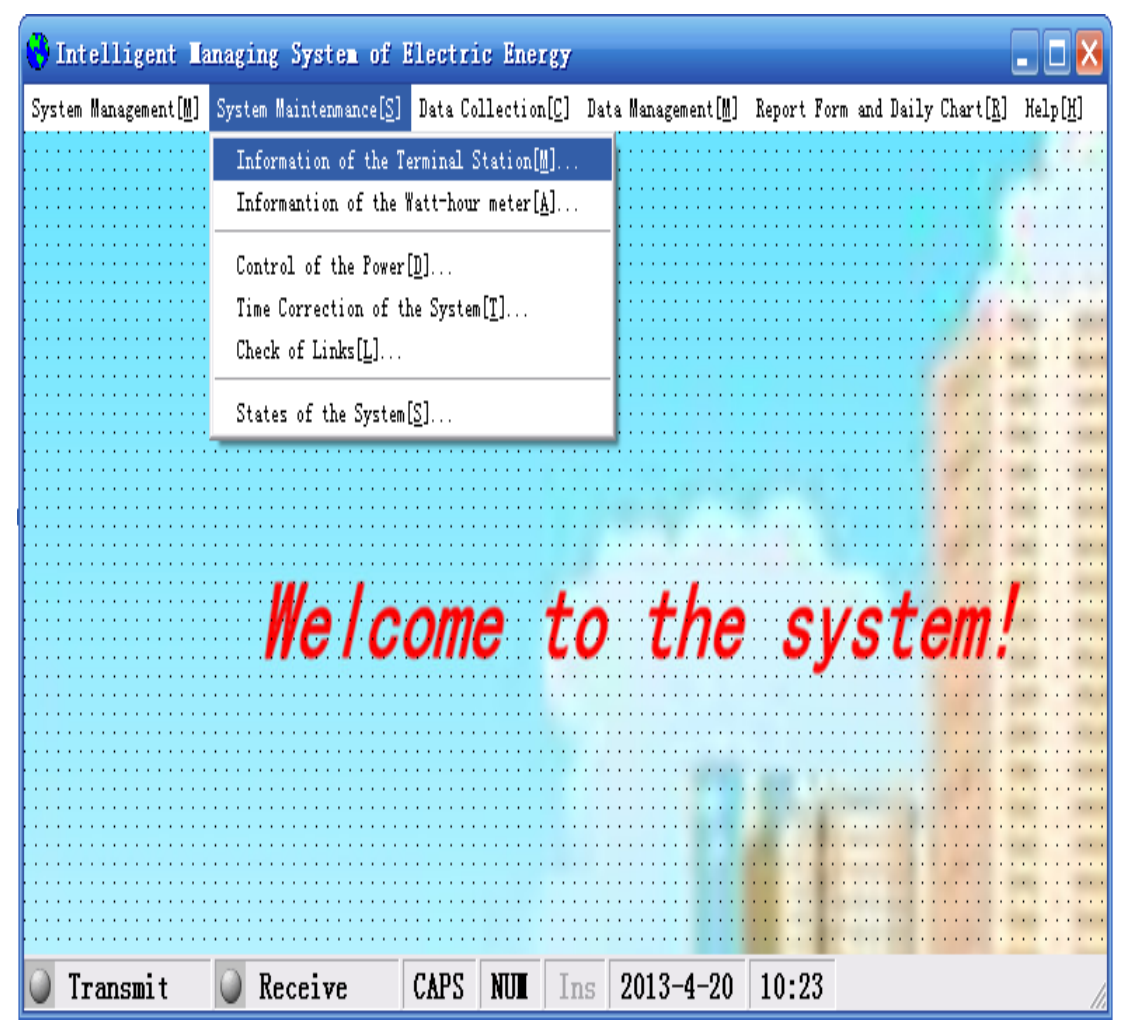

Figure 10. The Operation Interface of the Managing Subsystem

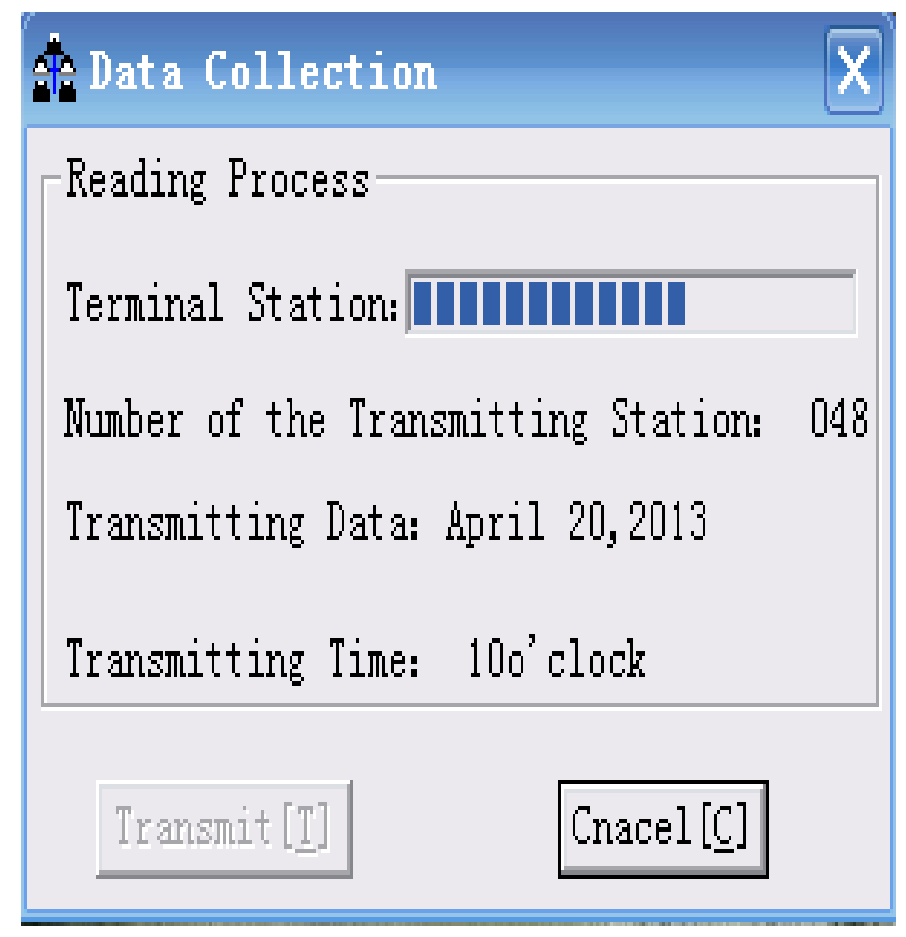

Figure 11. The Operation Interface of Collecting Data Automatically 


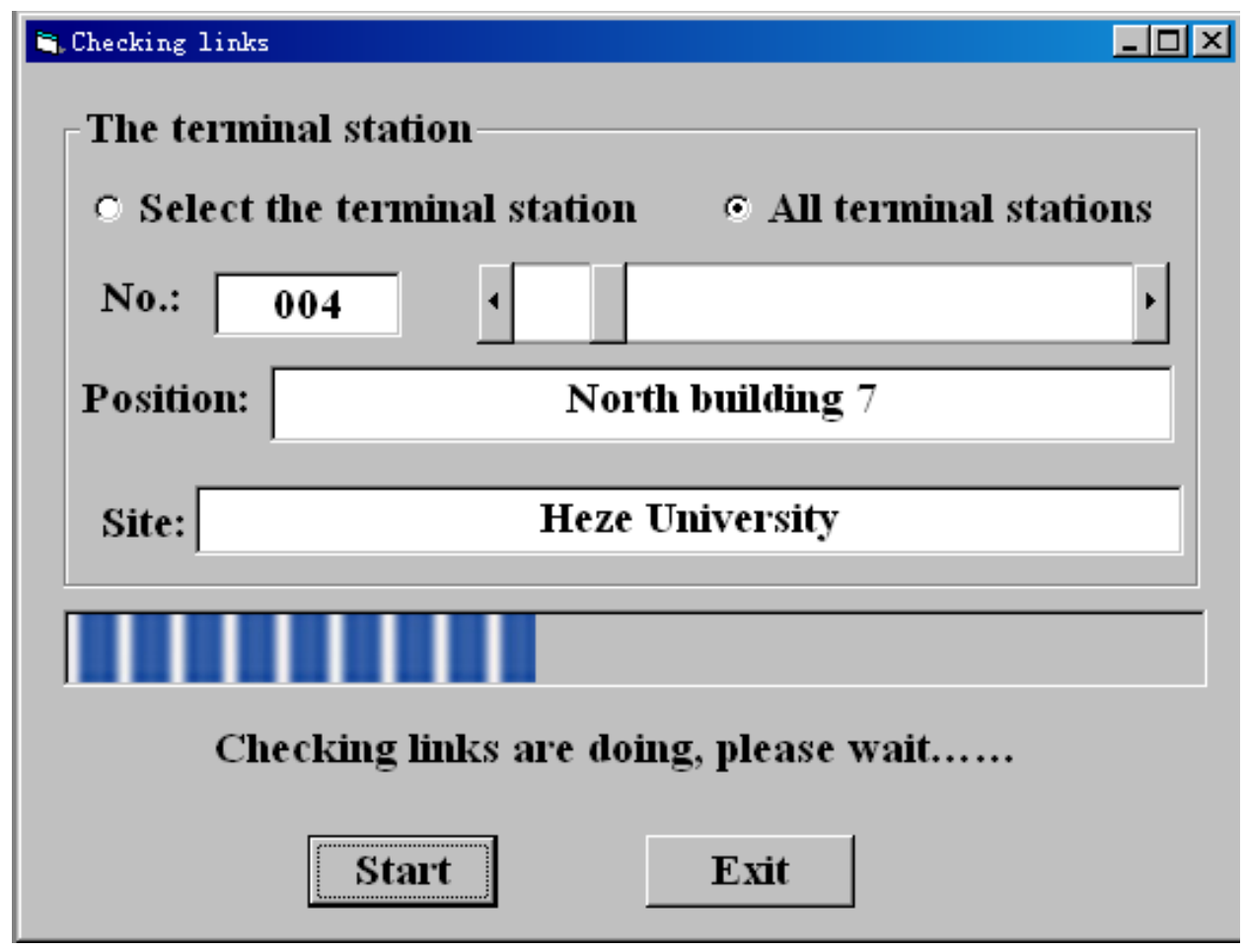

Figure 12. The Interface of Checking Links

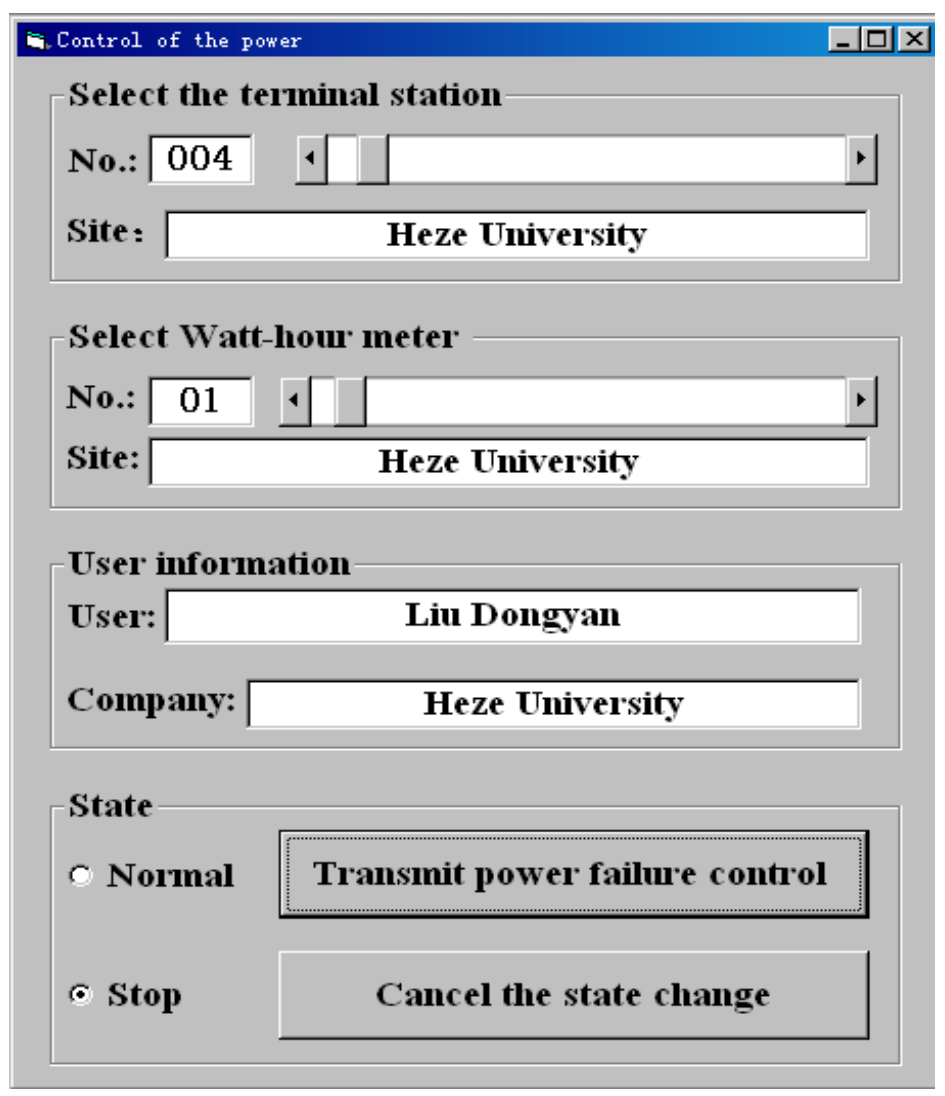

Figure 13. The interface of Control of the Power 


\begin{tabular}{|c|c|c|c|c|c|c|}
\hline \multicolumn{3}{|c|}{ A. Electric quantity inquiry } & \multicolumn{4}{|c|}{$-\mid \nabla x$} \\
\hline \multicolumn{7}{|c|}{ Select the terminal station } \\
\hline No.: & 004 & , & Time & Code & Time & Code \\
\hline \multirow{2}{*}{ Site: } & \multirow{2}{*}{\multicolumn{2}{|c|}{ Heze University }} & One o'clock & 118.17 & Thirteen o'clock & 118.21 \\
\hline & & & Two o'clock & 118.17 & Fourteen o'clock & 118.21 \\
\hline \multicolumn{3}{|c|}{ Select watt-hour meter- } & Three o'clock & 118.17 & Fifteen o'clock & 118.21 \\
\hline \multirow{2}{*}{ No.: } & \multirow{2}{*}{4} & \multirow{2}{*}{ 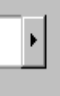 } & Four o'clock & 118.17 & Sixteen o'clock & 118.21 \\
\hline & & & Five o'clock & 118.17 & Seventeen o'clock & 118.21 \\
\hline \multirow{2}{*}{ Site: } & \multirow{2}{*}{\multicolumn{2}{|c|}{ Heze University }} & Six o'clock & 118.17 & Eighteen o'clock & 118.21 \\
\hline & & & Seven o'clock & 118.17 & Nineteen o'clock & 118.41 \\
\hline \multirow{2}{*}{\multicolumn{3}{|c|}{ Input data- }} & Eight o'clock & 118.17 & Twenty o'clock & 119.20 \\
\hline & & & Nine o'clock & 118.17 & Twentv-one o'clock & 119.80 \\
\hline & \multicolumn{2}{|c|}{ May 7,2013} & Ten o'clock & 118.17 & Twentv-two o'clock & 120.36 \\
\hline \multirow{2}{*}{\multicolumn{3}{|c|}{ User information- }} & Eleven o'clock & 118.21 & Twenty-three o'clock & 120.36 \\
\hline & & & Twelve o'clock & 118.21 & Zero o'clock & 120.36 \\
\hline User: & & & Total & \multicolumn{3}{|c|}{2.19} \\
\hline \multicolumn{3}{|c|}{ Position: North building 8} & \multicolumn{2}{|c|}{ Ok } & \multicolumn{2}{|l|}{ Exit } \\
\hline
\end{tabular}

Figure 14. The Interface of Electric Quantity Inquiry

\begin{tabular}{|c|c|c|c|c|c|c|c|}
\hline \multicolumn{5}{|l|}{ 5. Electricity bill } & & & $-I E$ \\
\hline \multicolumn{5}{|c|}{ Select terminal station } & \multicolumn{3}{|c|}{ Watt-hour meter } \\
\hline No.: 003 & 1 & & & - & Meter: 03 & 4 & - \\
\hline \multicolumn{5}{|c|}{ Site: $\quad$ Heze University } & Position: & \multicolumn{2}{|c|}{ North building 7} \\
\hline \multicolumn{6}{|l|}{ Data } & Payment $[\mathrm{P}]$ & Find[F] \\
\hline \multirow[t]{2}{*}{ Account time: } & \multirow{2}{*}{\multicolumn{5}{|c|}{ March, 2013}} & \multirow[b]{2}{*}{ Print $[\mathbf{P}]$} & \\
\hline & & & & & & & Exit[E] \\
\hline \multicolumn{8}{|c|}{ Electrcity bill } \\
\hline No. & \multicolumn{3}{|c|}{\begin{tabular}{|l|l|}
00303 & User \\
\end{tabular}} & \multicolumn{2}{|c|}{ Zhang Ming } & & \\
\hline Time & \multicolumn{2}{|c|}{\begin{tabular}{|l|l|} 
April, 2013 & Compony \\
\end{tabular}} & \multicolumn{3}{|c|}{ Heze University } & & \\
\hline Start time & March 1, 2013 & \multicolumn{2}{|c|}{ End time } & \multicolumn{2}{|c|}{ March 31, 2013} & & \\
\hline Start code & 26.74 & End c & code & 32.9 & & & \\
\hline Period time & \multicolumn{2}{|c|}{ Period consumption } & \multicolumn{2}{|c|}{ Period price } & Period money & Total power & Total money \\
\hline Normal time & \multicolumn{2}{|l|}{4.69} & \multicolumn{2}{|c|}{0.5} & 2.34 & \multirow{2}{*}{6.21} & \multirow{2}{*}{2.80} \\
\hline Discount time & 1.52 & & & 0.3 & 0.46 & & \\
\hline Month's pay & \multicolumn{2}{|c|}{100.00 yuan } & & \multicolumn{2}{|c|}{ Banlance of paymen } & \multicolumn{2}{|c|}{97.20 yuan } \\
\hline
\end{tabular}

Figure 15. The Electricity Bill of Payment 
Table 1. Partial Information of Watt-Hour Meters of No. 3 Terminal Station

\begin{tabular}{|c|c|c|c|c|c|c|}
\hline $\begin{array}{c}\text { Watt-hour } \\
\text { meter }\end{array}$ & User & $\begin{array}{c}\text { Start } \\
\text { time }\end{array}$ & $\begin{array}{c}\text { End } \\
\text { time }\end{array}$ & $\begin{array}{c}\text { Start } \\
\text { code }\end{array}$ & $\begin{array}{c}\text { End } \\
\text { code }\end{array}$ & $\begin{array}{c}\text { Power } \\
\text { consumption(kwh) }\end{array}$ \\
\hline 01 & Li Jun & $8: 00$ & $9: 00$ & 87.17 & 87.67 & 0.05 \\
\hline 02 & Wang Ming & $9: 30$ & $10: 30$ & 52.10 & 52.11 & 0.01 \\
\hline 03 & Zhang Ming & $10: 50$ & $11: 50$ & 28.06 & 28.08 & 0.02 \\
\hline 04 & Li Si & $12: 00$ & $13: 00$ & 67.50 & 68.00 & 0.50 \\
\hline 05 & Zhang Haijun & $13: 17$ & $14: 17$ & 77.00 & 77.01 & 0.01 \\
\hline 06 & Yang Wuyi & $14: 30$ & $15: 30$ & 36.78 & 38.24 & 1.46 \\
\hline 07 & Jiang Dawei & $16: 00$ & $17: 00$ & 97.13 & 99.77 & 2.64 \\
\hline
\end{tabular}

\section{Conclusion}

The intelligent managing system is designed in order to meet with the growing needs of the society; it is used in residential area, factories, substations and other areas to manage data of electric energy. The system has many functions such as collecting data automatically, analysis data, and querying data and so on. Results of long-term experiment and application show that the system has characteristics of high technical level, good reliability, high accuracy, strong adaptability, small volume, low power, simple operation interface, easy installation and maintenance etc. The use of the system can greatly reduce the amount of labor in electric power companies, it has a positive effect on promoting the distribution automatically and realizing the time-sharing charging scheme, it will play an invaluable role in developing social economy, promoting and spreading science and technology.

\section{Acknowledgements}

The authors would like to thank the editors and anonymous reviewers for their valuable comments. This work was supported by the National Natural Science Foundation of Heze University (No.XY14KJ07).

\section{References}

[1] S. Mak and D. Radford, "Design considerations for implementation of large scale automatic meter reading systems", IEEE Transactions, vol. 1, no. 27, (2013).

[2] M. J. Silva and B. Whitney, "Evaluation of the potential for PLC to interface with use of the nationwide differential GPS network", IEEE Transactions on Power Delivery, vol. 2, no. 32, (2010).

[3] R. M. Vines, H. J. Trussel and L. J. Gales, "Noise on residential power distribution circuits", IEEE Trans on EMC, vol. 3, no. 56, (2004).

[4] M. D. Amor and M S Stao, "Digital transmission performance of carrier channel on distribution power line network", IEEE Transactions on Power Delivery, vol. 2, no. 17, (2007).

[5] D. Radford, "Spread-spectrum data leap through AC power wiring", IEEE Spectrum, vol. 11, no. 3, (1996).

[6] K. Maruyama, N. Kushlro and Y. Minagawa, "An optimized gateway controller for home automation and automatic meter reading system", IEEE International Conference on Consumer Electronics, vol. 6, no. $23,(\mathbf{2 0 0 3})$. 
[7] W. S. Zhong and Y. Wang, "Design of automobile intelligence security control system based on microcontroller AT89C51", Journal of Agricultural Machinery, vol. 1, no. 36, (2007).

[8] D. Pejic and V. Vujicic, "Accuracy limit of high-precision stochastic watt-hour meter", IEEE Transactions on Instrumentation and Measurement, vol. 3, no. 8, (2000).

[9] B. P. Lientz, E. B. Swansons and G. E. Tompkins, "Characteristics of application software maintenance", Communication of the ACM, vol. 6, no. 27, (2013).

[10] S. S. Yau and J. Collofello, "Some stability measures for software maintenance", IEEE Transactions on Software Engineering, vol. 6, no. 30, (2012).

[11] M. Z. Iskandarani and N. F. Shilbayeh, "Remote meter communication system for reading and billing", WSEAS Transactions on Communications, vol. 9, no. 17, (2009).

[12] L. Gang and D. Li, "Programming example explanation of Visual Basic 6.0", Electronic Industry publishers, Beijing, (2011).

\section{Author}

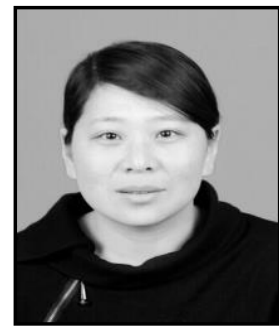

Qiu-xia Liu received the Master degree in Physical Electronics from Qufu Normal University of China. She is a lecturer at Heze University of Shandong province. Her major research direction is reseach and design of intelligent control systems. In recent years, she has published more than twenty paper in important journals at home and abroad, and has gotten many honores. 